\title{
GAMBARAN KINERJA DAN KETERIKATAN KERJA PADA PEGAWAI PENGELOLA BARANG/JASA PEMERINTAH
}

\author{
Umi Nurnaeni ${ }^{1}$ \\ Fakultas Psikologi, Universitas Tarumanagara Jakarta \\ Email: umi_nurnaeni@yahoo.com
}

\begin{abstract}
ABSTRAK
Lembaga X bertanggung jawab sebagai instansi pembina pegawai pengelola Pengadaan Barang/Jasa Pemerintah di seluruh Indonesia. Layanan pengadaan di setiap kementerian, lembaga dan pemerintah daerah belum banyak yang merupakan organisasi permanen, sehingga pegawai pengelola pengadaan memiliki pekerjaan ganda. Pekerjaan dalam pengadaan merupakan pekerjaan tambahan selain mereka mengejakan tugas utamanya. Maka penelitian ini bertujuan untuk melihat gambaran keterikatan kerja dan kinerja pegawai pengelola pengadaan barang/jasa pemerintah untuk memberikan masukan bagi Lembaga X dalam menentukan pola pembinaan yang tepat. Kinerja diartikan sebagai perilaku yang dilakukan secara sadar oleh para karyawan yang merupakan bentuk usaha untuk mencapai hasil sebagaimana yang sesuai dengan tujuan organisasi. Kinerja yang diteliti adalah kinerja individu berdasarkan teori dari Koopmans (2014) terdiri dari empat dimensi yaitu task performance, contextual performance, adaptive performance, dan contraproductive work behavior. Keterikatan kerja adalah keadaan dimana pegawai dapat berkomitmen penuh dengan pekerjaannya. Penelitian dilakukan secara kuantitatif dengan menggunakan alat ukur yaitu kinerja dan keterikatan kerja. Partisipan yang mengikuti penelitian ini sejumlah 179 orang, yang diambil dengan metode insidental sampling sesuai kriteria yang telah ditetapkan. Hasil penelitian memperlihatkan bahwa pegawai pengelola PBJ memiliki kinerja yang tinggi, mereka berupaya untuk berperilaku dan bertindak untuk kesuksesan organisasinya. Tiap dimensi dalam variabel keterikatan kerja memiliki rata-rata skor diatas nilai tengah alat ukur sehingga dapat diartikan bahwa keterikatan kerja partisipan tinggi, tertinggi pada dimensi dedication.
\end{abstract}

Kata kunci: kinerja, keterikatan kerja,

\section{PENDAHULUAN}

\section{Latar Belakang}

Anggaran Belanja Negara Republik Indonesia pada tahun 2017 mencapai Rp 2.080 triliun yang digunakan untuk belanja pemerintah pusat dan belanja daerah, hal tersebut tidak akan lepas dari proses pengadaan barang/jasa pemerintah (PBJ). Karena pengadaan barang/jasa berperan penting dalam pembangunan, maka PBJ diharapkan dapat berlangsung secara lebih efektif dan efisien, mengutamakan penerapan prinsip-prinsip persaingan usaha yang sehat, transparan, terbuka, adil, serta dapat dipertanggungjawabkan.

Pegawai pengelola PBJ memegang peranan penting dalam melaksanakan proses pengadaan agar tujuan pengadaan nasional tercapai. Sesuai dengan visi Lembaga $X$ yang bertanggungjawab terhadap regulasi pengadaan barang/jasa pemerintah, pengadaan seharusnya memiliki konsep berkelanjutan (sustainable procurement), yang dapat diartikan bahwa pengadaan tidak hanya terbatas pada mendapatkan barang, bangunan dan jasa namun juga untuk mencapai value for money. Value for money dapat diartikan perbesaran nilai dari uang yang dikeluarkan dan memberikan manfaat nyata untuk masyarakat dan ekonomi dengan turut serta meminimalkan kerusakan lingkungan (Simatupang \& Kartika., 2013).

Fenomena yang terjadi, berdasarkan kajian yang dilaksanakan oleh Direktorat Penelitian dan Pengembangan Komisi Pemberantasan Korupsi pada tahun 2015, permasalahan umum dalam pengadaan barang dan jasa adalah in efficiency yaitu harga yang diperoleh melalui proses 
pengadaan barang dan jasa cenderung lebih tinggi dibandingkan pembelian langsung/harga pasar, lemahnya daya saing nasional dan pendekatan yang protektif.

Hasil pengadaan juga dikeluhkan oleh masyarakat, seperti yang diberitakan bahwa konstruksi untuk perbaikan jalan yang cepat rusak (Riyana, 2016), perbaikan jalan di Jawa Barat belum dapat maksimal karena proses lelang lambat ("Mengapa perbaikan jalan Jawa Barat tak maksimal" 4 April 2017). Cepat rusaknya barang hasil pengadaan dan in efficiency dalam pengadaan memperlihatkan bahwa terdapat indikasi permasalahan perilaku dan tindakan pegawai PBJ dalam melaksanakan proses pengadaan sehingga belum mencapai visi pengadaan yaitu value for money.

Tujuan pengadaan nasional dapat tercapai apabila didukung dengan perilaku dan tindakan pegawai pelaksana proses pengadaan yang sesuai dengan apa yang akan dicapai oleh organisasi dalam hal ini adalah pemerintah. Camphell (dalam Kopmanss., 2014) menyatakan bahwa perilaku dan tindakan individu yang sesuai dengan tujuan dari organisasi dinamakan kinerja. Menurut Gibson (2011) kinerja dipengaruhi oleh variabel individual, organisasional dan psikologis. Variabel individu dipengaruhi oleh kemampuan, keterampilan, latar belakang pribadi dan demografis. Variabel organisasional terdiri dari variabel sumber daya, kepemimpinan, imbalan, struktur dan desain pekerjaan.

Terdapat kondisi lain bahwa banyak pegawai pengadaan barang/jasa yang belum menjadi pegawai tetap di layanan pengadaan, pekerjaan pengadaan masih menjadi pekerjaan tambahan disamping pekerjaan utamanya di instansi. Sehingga untuk dapat melaksanakan dua pekerjaan, pegawai pengelola PBJ untuk menyelesaikannya banyak yang memperlihatkan antusiasme, dan pada saat istirahat tampak ada pegawai yang masih berkutat dengan pekerjaan dan bersedia pulang larut malam atau dengan kata lain pegawai sulit untuk lepas dari pekerjaan yang sedang dihadapinya. Pekerja yang terikat dengan pekerjaannya menyadari konteks bisnis dan kerja dengan rekan- rekannya sesama pekerja untuk kemudian meningkatkan kinerja dalam pekerjaan untuk kepentingan organisasi (Robinson et al., 2004).

Bakker, et al (2012) menyatakan bahwa keterikatan kerja berhubungan positif dengan dengan kinerja, akan menimbulkan emosi positif dan kesehatan fisik yang baik. Seseorang yang terlibat dengan pekerjaannya tidak hanya tertarik terhadap aspek pekerjaan yang memberi makna tetapi mereka secara aktif mencarinya dalam pekerjaan mereka sebagai sarana untuk tetap berkomitmen terhadap organisasi. Pegawai menjadi lebih terlibat, mereka menganggap pekerjaan mereka lebih bermakna, memuaskan diri sendiri dan memberi inspirasi dan pada gilirannya akan lebih berdedikasi serta berkonsentrasi pada pekerjaanya mengarah pada kinerja yang superior (Park, \& Gursoy, 2012).

Berdasarkan hal-hal tersebut diatas, peneliti tertarik untuk melihat gambaran kinerja dan keterikatan kerja pegawai pengelola PBJ agar dapat menjadi masukan bagi Lembaga $\mathrm{X}$ untuk dalam menentukan strategi peningkatan kapasitas sumber daya pengelola pengadaan. Tujuan peningkatan kapasitas sumber daya manusia pengelola pengadaan barang/jasa adalah terwujud SDM yang menjunjung tinggi semangat profesionalisme, meskipun pegawai pengelola PBJ berada dalam instansi masing-masing namun pembinaan dan pengembangan SDM terus dilakukan oleh pemerintah pusat dan daerah agar pegawai pengadaan memiliki kinerja yang baik. 


\section{TEORI}

\section{Kinerja}

Menurut Campbell (dalam Sonnetag, 2002), kinerja diartikan sebagai permintaan dari organisasi kepada pada pekerjanya untuk dapat dilakukan dan dikerjakan dengan baik. Kinerja bukan sekedar sebuah tindakan, namun lebih pada penilaian dan proses evaluasi.

Sedangkan menurut Koopmans (2014) mendefinisikan kinerja pola perilaku dan tindakan dari para karyawan yang relevan dengan tujuan organisasi. Kinerja ini lebih menekankan pada pola perilaku dan tindakan karyawan dibandingkan dengan hasil dari perilaku itu sendiri. Hal ini berisi perilaku yang berada dibawah kontrol dari individu itu sendiri, kecuali perilaku tersebut dipengaruhi oleh lingkungannya.

Menurut Koopsman (2014) terdapat empat jenis dari kinerja, yaitu: task performance, contextual performance, adaptive performance, dan contraproductive work behavior. Dimensi pertama, task performance adalah kecakapan (contoh : kompetensi) individu untuk dapat melakukan sebuah tugas. Terdapat lima hal yang menjadi bagian dari task performance : job-spesific task proficiency, non-job-spesific task proficiency, written and oral communication, supervision/leadership, management/administration.

Kedua, contextual performance cenderung kepada aktivitas yang tidak berkontribusi pada technical core tapi mendukung organisasi, sosial, dan lingkungan psikologis yang ingin dicapai oleh organisasi. Ketiga, adaptive performance didefinisikan sebagai kemampuan individu untuk mengubah perilaku individu tersebut untuk menyesuaikan dengan tuntuntan lingkungan kerja. Pekerja yang memiliki adaptive performance yang tinggi di sebuah organisasi cenderung memiliki keuntungan dalam kesempatan kerja dibandingkan pekerja yang tidak bisa (Pulakos, Arad, Donovan, \& Plamondon, 2000).

Keempat, counterproductive work behavior terdiri dari tindakan yang disengaja oleh karyawan yang membahayakan organisasi atau pemegang saham. Perilaku karyawan yang bertujuan untuk menyakiti organisasi mereka atau anggota organisasi, seperti pencurian, sabotase, agresi, interpersonal, cara kerja yang lambat, membuang-buang waktu dan menyebarkan rumor atau gosip. Berdasarkan beberapa definisi tersebut, dapat disimpulkan bahwa counterproductive work behavior merupakan tindakan yang disengaja yang bertujuan untuk menyakiti organisasi mereka atau anggota organisasi.

\section{Keterikatan Kerja}

Schaufeli et al., (2004) mengartikan keterikatan kerja sebagai positivitas, pemenuhan kerja dari pusat pikiran yang memiliki dimensi yaitu vigor, dedication dan absorption. Vigor adalah level energi yang tinggi, adanya kemauan untuk investasi tenaga, persistensi, tidak mudah lelah. Dedication adalah keterlibatan yang kuat ditandari oleh antusiasme, rasa bangga, dan inspirasi. Absorption adalah keadaan total immersion pada pekerjaan yang dikarakteristikkan oleh cepatnya waktu berlalu dan sulitnya memisahkan dari pekerjaannya. 


\section{METODE PENELITIAN}

\section{Karakteristik Partisipan}

Partisipan yang masuk kriteria penelitian ini adalah pegawai pengelola pengadaan barang/jasa pemerintah, yaitu aparatur sipil negara yang ditugaskan atau berpengalaman dalam proses pengadaan barang/jasa. Partisipan sejumlah 185 orang namun yang terpakai sejumlah 179 data, 6 responden hanya mengisi sepuluh persen dari seluruh kuesioner sehingga tidak dipakai.

Tabel 1 Gambaran partisipan berdasarkan jenis kelamin

\begin{tabular}{|c|c|c|}
\hline Jenis kelamin & Jumlah & Persentase \\
\hline Laki-laki & 158 & $88 \%$ \\
\hline Wanita & 21 & $12 \%$ \\
\hline Total & 179 & $100 \%$ \\
\hline
\end{tabular}

Tabel 2 Gambaran partisipan berdasarkan tingkat pendidikan

\begin{tabular}{|c|c|c|}
\hline Tingkat Pendidikan & Jumlah & Persentase \\
\hline SMA & 1 & $0,005 \%$ \\
\hline D3 & 2 & $0,1 \%$ \\
\hline S1 & 95 & $53 \%$ \\
\hline S2 & 76 & $42 \%$ \\
\hline S3 & 5 & $3 \%$ \\
\hline Total & 179 & $100 \%$ \\
\hline
\end{tabular}

Tabel 3 Gambaran partisipan berdasarkan wilayah bekerja

\begin{tabular}{lcc}
\hline \multicolumn{1}{c}{ Wilayah } & Jumlah & Persentase \\
\hline Pulau Jawa & 129 & $72 \%$ \\
Pulau Sulawesi & 12 & $7 \%$ \\
Pulau Kalimantan & 8 & $4 \%$ \\
Pulau Sumatera & 25 & $14 \%$ \\
Pulau Maluku dan Papua & 1 & $1 \%$ \\
Pulau Sunda Kecil & 4 & $2 \%$ \\
\hline Total & 179 & $100 \%$ \\
\hline
\end{tabular}

\section{Pengukuran Penelitian}

Untuk mengukur kinerja dari karyawan, peneliti menggunakan alat ukur yang diadaptasi dari teori yang dikemukakan oleh Koopmans (2014) yang terdiri dari 47 butir pertanyaan dengan skala Likert satu sampai lima. Pada alat ukur ini, partisipan diminta menjawab pertanyaan dengan skala satu sampai lima. Skala satu menunjukan tingkat paling rendah dari pengukuran dimensi tersebut, sedangkan skala lima adalah skala tertinggi. Semakin tinggi skor pada variabel ini berarti partisipan semakin dapat menjalankan tugasnya dan mencapai tujuan perusahaan.

Terdapat 13 butir pernyataan yang mengukur dimensi task performance dari kinerja, yang seluruhnya terdiri dari butir positif. Contoh butir pernyataannya adalah "Saya merencanakan pekerjaan saya sehingga dapat diselesaikan tepat waktu". Nilai reliabilitas internal pada dimensi ini sebesar 0,883 .

Dimensi kedua adalah contextual performance terdiri dari 16 butir yang seluruhnya adalah item positif. Contoh butirnya berbunyi seperti "Saya dapat bekerjasama dengan baik, "Saya mengambil inisiatif pada saat ada masalah yang harus diselesaikan". Nilai reliabilitas internal pada dimensi ini sebesar 0,895.

Dimensi ketiga yaitu adaptive performance. Dimensi ini memiliki 8 butir pernyataan yang seluruhnya merupakan pernyataan positif. Contoh butir adalah "Saya dapat mengatasi dengan 
baik situasi sulit dan kemunduran-kemunduran saat bekerja.". Nilai reliabilitas internal pada dimensi ini sebesar 0.904 .

Dimensi keempat yaitu counter productive behavior $(C W B)$. Dimensi ini memiliki 10 butir pernyataan yang seluruhnya merupakan pernyataan positif namun bermakna negatif. Contoh butir adalah "Saya sengaja meninggalkan pekerjaan saya sehingga orang lain harus menyelesaikannya". Nilai reliabilitas internal pada dimensi ini sebesar 0.854 .

Untuk mengukur keterikatan kerja responden, peneliti menggunakan adaptasi dan pengembangan dari Utrech Work Engagement Scale (UWES) yang dikembangkan oleh Bakker et al., (2006) terdiri dari tiga dimensi yaitu Vigor, Dedication dan Absorption. Alat ukur terdiri dari 9 pernyataan. Dimensi pertama yaitu vigor. Dimensi ini memiliki 3 butir pernyataan yang seluruhnya merupakan pernyataan positif. Contoh butir adalah "Saya merasa sangat kuat dan bertenaga mengerjakan pekerjaan saya". Dimensi kedua yaitu dedication. Dimensi ini memiliki 3 butir pernyataan yang seluruhnya merupakan pernyataan positif. Contoh butir adalah "Saya merasa senang saat saya bekerja secara intensif". Dimensi ketiga yaitu absorption. Dimensi ini memiliki 3 butir pernyataan yang seluruhnya merupakan pernyataan positif. Contoh butir adalah "Saat bekerja, saya terbawa dengan pekerjaan saya". Secara keseluruhan sembilan butir pernyataan pada variabel keterikatan kerja, memiliki nilai reliabilitas internal pada dimensi ini sebesar 0.855 .

\section{HASIL DAN PEMBAHASAN}

\section{Gambaran Kinerja pada Partisipan}

Alat ukur Kinerja memiliki skala 1-5, dengan nilai tengah alat ukur adalah tiga. Untuk melihat gambaran tingkat kinerja partisipan, dapat dilihat pada tabel 4.

Tabel 4 Gambaran Variabel Kinerja

\begin{tabular}{|c|c|c|c|c|c|c|}
\hline Dimensi & Min & Max & SD & $\begin{array}{c}\text { Nilai } \\
\text { Tengah } \\
\text { skala }\end{array}$ & Mean & Intepretasi \\
\hline $\begin{array}{l}\text { Task } \\
\text { perfomance }\end{array}$ & 2.25 & 5.00 & .56085 & 3,0000 & 3.9581 & \multirow{4}{*}{$\begin{array}{l}\text { Dimensi task performance, contextual } \\
\text { performance dan adaptive } \\
\text { performance memiliki rata-rata skor } \\
\text { diatas nilai tengah alat ukur, sedangkan } \\
\text { dimensi CWB berada di bawah nilai } \\
\text { tengah alat ukur sehingga dapat } \\
\text { diartikan bahwa kinerja partisipan } \\
\text { tinggi. }\end{array}$} \\
\hline $\begin{array}{l}\text { Contextual } \\
\text { perfomance }\end{array}$ & 2.44 & 5.00 & .64823 & 3,0000 & 3.7552 & \\
\hline $\begin{array}{l}\text { Adaptive } \\
\text { perfomance }\end{array}$ & 2.50 & 5.00 & .68561 & 3,0000 & 3.7367 & \\
\hline CWB & 1.00 & 3.00 & .38296 & 3,0000 & 1.5089 & \\
\hline
\end{tabular}

Untuk kategori task perfomance memiliki mean $3.9581>3,0000$ berarti rata-rata kecakapan pegawai PBJ untuk dapat melakukan sebuah tugas tergolong lebih tinggi dari nilai tengah. Pada kategori contextual performance memiliki nilai rata-rata 3.7552 yang tergolong lebih tinggi dari nilai tengah juga. Pada kategori adaptive performance memiliki mean 3.7367 yang tergolong tinggi. Serta pada dimensi counter productive behavior memiliki mean 1.5089 .

\section{Gambaran Variabel Kinerja berdasarkan Data Demografi}

Berdasarkan data penelitian, dilakukan uji beda kelompok untuk mengetahui terdapat perbedaan signifikan atau tidak pada masing-masing kelompok. Hasilnya dapat dilihat pada tabel 5. 
Tabel 5 Gambaran Variabel Kinerja berdasarkan Data Demografi

\begin{tabular}{|c|c|c|}
\hline Aspek & Kinerja & Intepretasi \\
\hline Usia & $\begin{array}{l}F=1.137 \\
\text { Sig }=.303\end{array}$ & $\begin{array}{l}\text { Sig }>0,05 \text { sehingga dapat diartikan tidak terdapat perbedaan yang } \\
\text { signifikan pada kinerja ditinjau dari usia }\end{array}$ \\
\hline Jenis kelamin & $\begin{array}{l}F=.123 \\
\text { Sig }=.726\end{array}$ & $\begin{array}{l}\text { Sig }>0,05 \text { sehingga dapat diartikan tidak terdapat perbedaan yang } \\
\text { signifikan pada kinerja ditinjau dari jenis kelamin }\end{array}$ \\
\hline Status pernikahan & $\begin{array}{l}F=.502 \\
\text { Sig }=.606\end{array}$ & $\begin{array}{l}\text { Sig }>0,05 \text { sehingga dapat diartikan tidak terdapat perbedaan yang } \\
\text { signifikan pada kinerja ditinjau dari status pernikahan }\end{array}$ \\
\hline Pendidikan & $\begin{array}{l}F=2.478 \\
\text { Sig }=.046\end{array}$ & $\begin{array}{l}\text { Sig }<0,05 \text { sehingga dapat diartikan terdapat perbedaan yang } \\
\text { signifikan pada kinerja ditinjau dari pendidikan. }\end{array}$ \\
\hline Agama & $\begin{array}{l}\mathrm{F}=.139 \\
\mathrm{Sig}=.870\end{array}$ & $\begin{array}{l}\text { Sig }>0,05 \text { sehingga dapat diartikan tidak terdapat perbedaan yang } \\
\text { signifikan pada kinerja ditinjau dari agama }\end{array}$ \\
\hline Jabatan & $\begin{array}{l}\mathrm{F}=2.301 \\
\mathrm{Sig}=.061\end{array}$ & $\begin{array}{l}\text { Sig }>0,05 \text { sehingga dapat diartikan tidak terdapat perbedaan yang } \\
\text { signifikan pada kinerja ditinjau dari jabatan }\end{array}$ \\
\hline Wilayah bekerja & $\begin{array}{l}F=1.335 \\
\operatorname{Sig}=.252\end{array}$ & $\begin{array}{l}\text { Sig }>0,05 \text { sehingga dapat diartikan tidak terdapat perbedaan yang } \\
\text { signifikan pada kinerja ditinjau dari wilayah bekerja }\end{array}$ \\
\hline Pengalaman kerja & $\begin{array}{l}\mathrm{F}=.928 \\
\mathrm{Sig}=.565\end{array}$ & $\begin{array}{l}\text { Sig }>0,05 \text { sehingga dapat diartikan tidak terdapat perbedaan yang } \\
\text { signifikan pada kinerja ditinjau dari pengalaman kerja }\end{array}$ \\
\hline
\end{tabular}

Pada aspek pendidikan, analisa memperlihatkan $F=2.478$ dengan signifikasi $.046<0,05$ memperlihatkan bahwa terdapat perbedaan yang signifikan pada kinerja ditinjau dari aspek pendidikan. Maka peneliti juga melihat mean kinerja pada tiap jenjang pendidikan dan hasilnya tertampil pada tabel 6 .

Tabel 6 Gambaran Kinerja berdasarkan Tingkat Pendidikan

\begin{tabular}{lcccccl}
\hline \multicolumn{1}{c}{ Pendidikan } & Min & Max & SD & $\begin{array}{c}\text { Nilai Tengah } \\
\text { skala }\end{array}$ & Mean & Intepretasi \\
\hline Sekolah Menengah Umum & 3.46 & 3.46 &. & 3,0000 & 3.4600 & Cukup \\
Diploma 3 & 3.87 & 4.87 & .50000 & 3,0000 & 4.3700 & Tinggi \\
Sarjana (S1) & 3.13 & 4.91 & .04699 & 3,0000 & 3.9523 & Tinggi \\
Master (S2) & 3.00 & 4.98 & .05737 & 3,0000 & 4.0249 & Tinggi \\
Doktor (S3) & 3.89 & 4.98 & .21949 & 3,0000 & 4.5380 & Sangat Tinggi \\
\hline
\end{tabular}

Hasil diatas memperlihatkan bahwa partisipan dengan jenjang pendidikan Doktor memiliki keterikatan kerja yang paling tinggi dibandingkan dengan jenjang pendidikan lainnya.

\section{Gambaran Keterikatan Kerja pada Partisipan.}

Alat ukur keterikatan kerja memiliki skala penilaian 0-6 dengan nilai tengah alat ukur sebesar 3.5. Untuk melihat gambaran kategori keterikatan kerja pada partisipan penelitian ini, dapat dilihat pada tabel 7 .

Tabel 7 Tabel Kategori Variabel Keterikatan Kerja

\begin{tabular}{lcccccc}
\hline \multicolumn{1}{c}{ Dimensi } & Min & Max & SD & $\begin{array}{c}\text { Nilai } \\
\text { tengah } \\
\text { skala }\end{array}$ & Mean & Intepretasi \\
\hline Vigor & 1.33 & 6.00 & .56085 & 3,5000 & 4.6425 & Tiap dimensi dalam variabel keterikatan \\
Dedication & 2.33 & 6.00 & .84855 & 3,5000 & 5.0466 & kerja memiliki rata-rata skor diatas nilai \\
Absorption & 2.00 & 6.00 & .99612 & 3,5000 & 4.4246 & $\begin{array}{c}\text { tengah alat ukur sehingga dapat diartikan } \\
\text { bahwa keterikatan kerja partisipan tinggi }\end{array}$ \\
\hline
\end{tabular}

Berdasarkan data yang ada, mean tertinggi pada dimensi dedication sebesar 5,0466 > 3,5000, yang dapat diartikan bahwa rata-rata partisipan memiliki keterlibatan yang kuat ditandai oleh antusiasme, rasa bangga yang tinggi. Meskipun mereka merangkap pekerjaan, namun pengelola PBJ memiliki rasa bangga dan antusiasme dalam bekerja di bidang pengadaan. 


\section{KESIMPULAN DAN SARAN}

\section{Kesimpulan}

Berdasarkan hasil analisis data yang ditemukan pada penelitian ini, disimpulkan bahwa pegawai pengelola PBJ memiliki kinerja yang tinggi, mereka berupaya untuk berperilaku dan bertindak untuk kesuksesan organisasinya. Secara demografi, tidak terdapat perbedaan yang signifikan pada kinerja pegawai pengelola PBJ ditinjau dari aspek usia, jenis kelamin, status pernikahan, agama, jabatan, wilayah bekerja dan pengalaman kerja. Terdapat perbedaan yang signifikan pada kinerja apabila ditinjau dari aspek pendidikan, jenjang pendidikan strata tiga memiliki rata-rata kinerja tertinggi dibanding jenjang lainnya. Tiap dimensi dalam variabel keterikatan kerja memiliki rata-rata skor diatas nilai tengah alat ukur sehingga dapat diartikan bahwa keterikatan kerja partisipan tinggi, tertinggi pada dimensi dedication. Meskipun mereka merangkap pekerjaan, namun pengelola PBJ memiliki rasa bangga dan antusiasme dalam bekerja di bidang pengadaan.

\section{Saran}

Berdasarkan hasil penelitian yang telah dilakukan, peneliti mengajukan saran metodologis dan saran praktis untuk menjadi bahan pertimbangan bagi penelitian selanjutnya.

1. Kinerja yang diukur merupakan pengukuran dengan pendapat partisipan sendiri, hal tersebut akan rentan bias dikarenakan individu akan cenderung menilai dirinya baik. Sehingga kedepannya, penilaian kinerja dapat dikombinasikan dengan dari penilaian atasannya atau rekan sejawatnya.

2. Melakukan penelitian lanjutan mengenai kinerja untuk dapat memperoleh informasi yang lebih mengenai aspek-aspek apa saja yang dapat mempengaruhi kinerja

3. Melakukan penelitian lanjutan mengenai keterikatan kerja untuk dapat memperoleh informasi yang lebih mengenai aspek-aspek apa saja yang dapat mempengaruhi keterikatan kerja, misal iklim dan budaya organisasi

4. Keterikatan kerja pegawai pengelola PBJ tergolong tinggi, Lembaga X disarankan agar dapat menjaga dan meningkatkan keterikatan kerja pegawai dengan membuat pedoman yang memberikan kenyamanan, serta memastikan keamanan pegawai dalam bekerja sehingga kinerja mereka semakin meningkat.

\section{Ucapan Terima Kasih}

Penulis mengucapkan terimakasih kepada Deputi PPSDM dan Kepala Pusat Pendidikan dan Pelatihan Lembaga X yang telah memberi kesempatan untuk melaksanakan penelitian ini.

\section{REFERENSI}

Bakker, A. B., \& Demerouti, E. (2014). Job demands-resources theory. Work and well-being (pp. 37-64). Chichester, UK: WileyBlackwell

Eliyya. (2016) Sering rusak, penilik sekolah ramai-ramai kembalikan motor dinas. Berita Jateng.net. Diunduh dari http://beritajateng.net/sering-rusak-penilik-sekolah-ramairamai-kembalikan-motor-dinas/

Bakker, A. B., \& Demerouti, E. (2006). The job demands-resources model: State of the art. Journal of Managerial Psychology, 22, 309-328 
Direktorat Penelitian dan Pengembangan Komisi Pemberantasan Korupsi (Litbang KPK). (2016). Kajian Pencegahan Korupsi pada Pengadaan Barang dan Jasa Pemerintah. Diambil dari http://kpk.go.id/id/berita/siaran-pers/3532-guna-cegah-korupsi-kpklakukan-kajian-terkait-pengadaan-barang-dan-jasa-pemerintah;

Gibson, J.L. (2011). Struktur Organisasi dan Manajemen. Jakarta: Erlangga

Kopmanss (2014). Measuring individual work performance. Amsterdam, NLD: Institute for health and care research

Park, J.D., Gursoy, (2012). Generation effects on work engagement among U.S. hotel employess. International Journal of Hospitality Management. 29, 743-750

Penney, L. M., \& Spector, P. E. (2002). Narcissism and counterproductive work behavior: Do bigger egos mean bigger problems?. International Journal of Selection and Assessment, $10(1 / 2): 126-134$.

Pulakos, E.D., Arad, S., Donovan, M.A., Plamondon, K.E. (2000). Adaptability in the workplace: Development of a taxonomy of adaptive performance. Journal of Applied Psychology, 85(4), 612-624

Robinson, D. Perryman S. \& Hayday, S. (2004). The drivers of employee engagement. Falmer, UK: Institute for Employment Studies.

Riyana, O. (2016). Jalan gampang rusak, netizen ngadu ke walikota. Radar Cirebon. Diunduh dari http://www.radarcirebon.com/jalan-gampang-rusak-netizen-ngadu-ke-walikota.html

Salanova, M \& Schaufeli. (2008). A cross-national study of work engagement as a mediator between job resources and proactive behaviour. The International Journal of Human Resource Management. 19(1), January 2008, 116-131

Schaufelli, W.B. \& Bakker, A.B. (2004). Job demands, job resources, and their relationship with burnout and engagement: a multi-sample study. Journal of Organizational Behavior, 25 (3) 293-315. Diunduh dari J. Organize. Behav.25.www.interscience.wiley.com. doi : 10.1002/job. 248

Simatupang, T.M. \& Kartika, F,. (2013). Manajemen Pengadaan Publik. Jurnal pengadaan. 3 (3)

Tempo. (2017, April 4). Mengapa perbaikan jalan Jawa Barat tak maksimal. - proses lelang lambat. Tempo. Diunduh dari https://bisnis.tempo.co/read/862644/mengapa-perbaikanjalan-jawa-barat-tak-maksimal. 